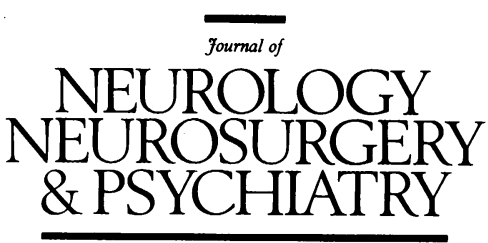

\title{
Editorial
}

\section{From thalamic syndrome to central poststroke pain}

Chronic pain sometimes follows a stroke. This is often thought to be an unusual, if not rare, occurrence, and it took over 10 years for Bowsher to amass the 130 patients with pain from stroke and subarachnoid haemorrhage reported in this fournal. ${ }^{1}$ Yet in the first prospective study reported last year, Andersen and colleagues showed that as many as $8 \%$ of patients have persistent pain a year after their stroke. ${ }^{2}$ Although only a small proportion of stroke victims will have chronic pain, because stroke is so common, pain must affect surprisingly large numbers of people, many of whom will not necessarily be under medical review. The purpose of this editorial is to draw attention to the importance of this "hidden" disorder, place it within the context of central pain, and briefly summarise some clinical aspects and possible mechanisms.

Pain after stroke is an example of central pain, defined as "regional pain caused by a primary lesion or dysfunction in the CNS, usually associated with abnormal sensibility to temperature and to noxious stimulation." 3 (For reviews on central pain, see ${ }^{4-7}$; for a historical review of the terminology and development of the concept, see $^{8}$.) Whereas stroke is the commonest cause, followed by multiple sclerosis $^{9-11}$ and spinal cord injury, ${ }^{12}$ there are numerous other neurological disorders that can give rise to central pain; cerebral causes include tumours, ${ }^{13}$ penetrating head injuries, ${ }^{14}$ epilepsy, ${ }^{15-17}$ Parkinson's disease, ${ }^{1819}$ and motor neuron disease ${ }^{20}$; and spinal causes include syringomyelia, ${ }^{2122}$ spinal cord infarction, ${ }^{2}$ and tumours. ${ }^{46}$ Central pain may also follow surgical lesions of the nervous system, ${ }^{624}$ but curiously it rarely follows blunt head injury or craniotomy. Pain after stroke can be considered the epitome of central pain, and many of the clinical features and therapeutic strategies employed in this condition are common to other conditions causing central pain.

From thalamic syndrome to central poststroke pain The finding that strokes could give rise to pain became established in 1906 with the famous paper entitled Le syndrome thalamique by Dejerine and Roussy. ${ }^{25}$ They described the postmortem findings in three patients who had pain that followed stroke. They also correlated the clinical features with the pathological findings of a lesion that included "the external nucleus of the thalamus (lateral and posterior portions especially) ....", and defined the thalamic syndrome-a term they introduced-as a mild hemiplegia without contractures, persistent superficial hemianaesthesia (in some cases replaced by superficial hyperaesthesia) with impaired deep sensation, mild hemiataxia and astereognosis, and in addition there might be choreoathetosis on the paralysed side and "sharp, enduring, paroxysmal, often intolerable pain on the hemiplegic side which does not respond to any analgesic treatment". ${ }^{25}$
Despite Dejerine and Roussy ${ }^{25}$ reporting that pain was an inconstant feature, the thalamic syndrome is oftenincorrectly-thought of as being synonymous with pain that follows stroke. Furthermore, it soon became apparent that similar pain could arise after strokes that affect not just the thalamus but many and possibly any part of the central somatosensory pathways. ${ }^{4}$ As a result, the term "thalamic syndrome" for the painful condition is neither historically correct nor accurate in respect of the clinical features and has been replaced by the term "central poststroke pain".

\section{The nature of the vascular lesion}

Why some, and possibly younger, ${ }^{1}$ patients should develop pain, why most strokes remain painless, and why pain tends not to occur when there is severe hemiplegia are unknown. There is no relation between the pain and the arterial territory involved, nor the size of the lesion, and no single structure has been implicated in the generation of the pain.

Studies with $\mathrm{CT}^{26}$ and more recently $\mathrm{MRI}^{27}{ }^{28}$ have disclosed the numbers and sites of vascular lesions which may be giving rise to pain. Sometimes multiple, these lesions often include small infarcts especially in the brainstem, and tiny infarcts could account for the pain in those patients in which this is the only symptom. Often, however, it is difficult to correlate any specific lesion on the scan with the site of origin of the pain. Very infrequent after midbrain infarcts, pain is commonest after thalamic infarcts but even then it is unusual; Bogousslavsky et al reported pain in only three of 42 patients with thalamic infarcts established by $\mathrm{CT}$, and in all three there was infarction affecting the ventroposterior thalamus. ${ }^{29}$ Poststroke pain is also well recognised after cortical and subcortical infarcts affecting the parietal region, and the term parietal pseudothalamic pain has been used in this context. ${ }^{30}$

Infarcts are not the only vascular disorders causing poststroke pain. Pain can occur after intracerebral and subarachnoid haemorrhage ${ }^{31}$ (independent of neurosurgical intervention ${ }^{1}$ ), although the contribution of spasm and infarction after subarachnoid haemorrhage remains unclear. Pain that resolved after decompressive surgery has also been reported in association with an unruptured aneurysm that projected into the thalamus. ${ }^{32}$

Rarely, pain may be abolished by another stroke. ${ }^{33}$

\section{Clinical features}

Most of the clinical features of central poststroke pain have been recognised for decades. ${ }^{4}$ Delay in onset of the pain, often by days or weeks, sometimes for months, and occasionally for many years, is striking. ${ }^{46}$ The pain may 
unfortunately gradually develop as sensory impairment and weakness ${ }^{1}$ improve, and the pain may then remain constant and often permanent although variable in intensity. The pain, which can be very severe, may be superficial or deep, is typically burning ${ }^{146}$ with an ice-like quality, ${ }^{1}$ but may also be aching, tearing, squeezing, or stabbing, and the pain tends to be worsened by emotion, diurnal factors, movement, ${ }^{14}$ and sometimes electrical stimulation. ${ }^{34}$ There may also be spontaneous or evoked sensory disturbances such as paraesthesiae, dysaesthesiae, hyperpathia, allodynia to cold, touch or movement, radiation of cutaneous stimuli, and aftersensations. Pain is often unilateral (with about equal right-left distribution ${ }^{1}$ ) and affects one half of the body, but may also occur in an unusual distribution-for instance, in a quadrant of the body, or around one side of the face, or the mouth and hand (the cheiro-oral syndrome). ${ }^{36}$

Recently the sensory changes accompanying the pain have been studied more extensively. The area of pain is within or less than that of the sensory deficit, ${ }^{28}$ which often shows allodynia or hyperalgesia. The cardinal findings are that appreciation of pinprick and temperature is nearly always impaired, ${ }^{12635}$ and there is almost always a raised threshold to warm and cold detection and to a lesser extent also to painful heat and pain. ${ }^{28}{ }^{35}$ Modalities subserved by the posterior columns are less commonly affected, although in patients with poststroke pain, dysaesthesiae after physiological stimuli including light touch and movement or electrical stimulation are probably mediated by the posterior columns. ${ }^{37}$

Confirmation of the typical spinothalamic dysfunction and small fibre mediated involvement has come from evoked potential studies. These demonstrate that laser evoked cerebral potentials are usually abnormal when elicited from the affected side of patients with poststroke pain and in whom there is impairment of spinothalamic function, ${ }^{38}$ compared with normal electrically evoked sensory potentials subserved by large diameter fibres. ${ }^{39}$ Patients with strokes and impaired spinothalamic function may, however, not experience pain, and it seems that a lesion affecting the spinothalamic system "is a necessary but not sufficient condition" for the development of poststroke pain. ${ }^{28}$

Patients often show features of autonomic impairment on the painful side. The painful area tends to be cooler and vasoconstricted; changes in sweating are inconstant. ${ }^{1}$

\section{Treatment}

It is distressing to patients and disheartening for doctors to realise that the original finding of Dejerine and Roussy ${ }^{25}$ as to the ineffectiveness of treatment remains true for the majority of patients, and many would not share the view that pain relief can be achieved in almost two thirds of patients. ${ }^{40}$ New approaches therefore remain the best hope for the future. The principles of treatment are first to treat any nociceptive components, related, for instance, to skin changes, infection, and musculoskeletal factors including abnormal posture. This is because these peripheral factors are generally easier to treat than the central pain, and because abnormal peripheral input may enhance central pain.

\section{DRUGS}

Numerous types of drugs ranging from phenothiazines to levodopa have been tried in the treatment of poststroke pain, and occasional patients unpredictably respond, for example, to anticonvulsants such as carbamazepine. ${ }^{41}$ Few drugs, however, have stood the test of time, and on the rare occasions that controlled studies have been under- taken, drugs such as naloxone which were initially thought valuable have often been found to be ineffective..$^{42}$

Most information pertains to tricyclic antidepressant drugs, and those with a non-selective chemical profile may be associated with greater efficacy. Some patients in pain who are also depressed may report that their depression has resolved yet their pain persists; this, and the fact that in some patients the relief of pain occurs more rapidly than might a typical antidepressant effect, suggest that such drugs mediate relief of pain independently of effects on depression ${ }^{4143}$ and thus through different mechanisms. Amitriptyline has been found to be more effective than placebo, and whereas considerable variation in dosage has been used, greater pain relief may be achieved when the plasma concentration is greater than $300 \mathrm{~nm} / 1 .{ }^{41}$ The most effective tricyclic antidepressant has not been established, although in pain associated with diabetic peripheral neuropathy, desipramine seemed as effective as amitryptiline. In practice it may be helpful to start with a low dose of tricyclic antidepressant at night-for example, 10 or $25 \mathrm{mg}$ amitriptyline-making increases slowly. If ineffective after two or three months, the drug should be slowly withdrawn and an alternative preparation can be tried. Sometimes drugs such as carbamazepine may be added, but the efficacy of such combinations has not been proved.

New approaches to drug therapy have resulted from developments in understanding possible underlying mechanisms of central pain. Whether opioids are effective remains unclear. This issue, controversial on scientific, ethical, and social grounds, has been reviewed by Dubner who called for "...more science, not more rhetoric, regarding opioids and neuropathic pain." ${ }^{44}$ The possible hyperexcitability of the damaged nervous system has been the rationale for further studies on local anaesthetic agents for treatment of central pain, including the use of local anaesthetics such as systemic lignocaine and the oral analogue mexiletine..$^{45}$ Adequate controlled trials are awaited.

Chronic pain may involve central NMDA-mediated mechanisms, and attempts have been made to develop NMDA receptor antagonists. Whereas oral dextromethorphan is ineffective in treatment of central pain, ${ }^{46}$ the use of subanaesthetic doses of intravenous, subcutaneous, and more recently oral ketamine seems promising, ${ }^{47}$ although reports are currently anecdotal. Whether its possible analgesic properties relate to ketamine or its primary breakdown product, nor-ketamine, remains unclear. ${ }^{48}$ If oral ketamine were to prove effective in the long term, its use would be an important advance.

The opposite approach, enhancement of inhibitory GABA mediated processes, is also being explored, and the beneficial use of intrathecal baclofen has been reported in central poststroke pain. ${ }^{49}$

\section{ABLATIVE AND STIMULATION PROCEDURES}

Many ablative procedures on the peripheral and central nervous system, particularly thalamotomy and mesencephalotomy, have been attempted to interrupt afferent pain conducting pathways. The realisation that neurogenic pain tends to be unaffected by such procedures and the tendency in successful cases for late recurrence of pain, however, have led to the abandonment of most destructive procedures "except in some very well defined and rare conditions." 50

Sympathetic blockade has been used, particularly when there is hyperpathia, but it is only rarely helpful. It is minimally invasive in experienced hands, although regional intravenous sympathetic blockade carries less risk. Curiously, this peripheral blockade has been reported as beneficial even when the cause of pain is central, although information from controlled studies is lacking. ${ }^{51}$ 
While enthusiasm for lesioning procedures has waned, there has been increasing interest in stimulation procedures, and various parts of the nervous system have been stimulated in an attempt to excite ill understood ascending or descending pathways that may subserve inhibitory processes. As with ablative techniques, few of these methods have been evaluated by appropriate controlled studies, any improvement in pain may wane, often only a few patients have been studied, patients included in trials often have heterogeneous conditions, and follow up tends to be for a short period and is rarely undertaken by independent observers.

A practical approach is to start with transcutaneous electrical nerve stimulation (TENS). This non-invasive and non-destructive technique is simple, safe, and cheap. It can be tried in almost any patient, and has been reported as occasionally improving central pain after strokes. ${ }^{34}$ However, TENS may exacerbate central pain during stimulation and obviously then needs to be discontinued.

Deep brain stimulation is invasive but relatively nondestructive..$^{52}$ The regions that have most commonly been stimulated include the somatosensory areas of the ventrobasal thalamus (including the ventroposterior lateral and medial nuclei), the periventricular and periaqueductal grey matter, and adjacent nuclei. There is uncertainty as to optimal stimulation sites and parameters of stimulation, and even the site of stimulation may not prove to be exactly that intended..$^{53}$ For the reasons stated above, it is not possible to assess the clinical efficacy of deep brain stimulation at present. ${ }^{52}$

Recently motor cortex stimulation has been developed. ${ }^{54}$ This site is of both practical and theoretical interest. Initial reports of benefit have, as usual, been followed by others that been less optimistic. ${ }^{55}$ Stimulation sometimes, but not always, ${ }^{56}$ produces tingling and vibration sensations but below threshold for muscle stimulation. Epilepsy has been reported as a complication. ${ }^{56}$ The rationale behind this technique, which relies on extradural stimulation of the premotor cortex, depends on stimulation of descending inhibitory non-nociceptive sensory pathways present in the motor cortex. PET studies of cerebral blood flow, however, suggest that this form of stimulation, which seems to be somatotopically mediated, may involve inhibitory processes and be related to increased synaptic activity in the ipsilateral thalamus and brainstem, as well as cingulate gyrus and orbitofrontal cortex. ${ }^{57}$

\section{BEHAVIOURAL AND PSYCHOLOGICAL APPROACHES}

Patients with chronic pain often find their pain not only extremely unpleasant but distressing to a degree that it seriously affects their lives. The role of behavioural therapists and psychologists in helping these patients is often invaluable, and many techniques have been employed. ${ }^{58}$ Not infrequently psychiatric advice may also be appropriate.

\section{Mechanisms}

The mechanisms subserving poststroke and other central pains have been considered for a century and remain unknown. Whereas there has been recent interest in the effects of plasticity ${ }^{59}$ and in alterations of affective processes in the anterior cingulate ${ }^{60}$ and subfrontal cortex in respect of how pain in humans is experienced, two main mechanisms have been postulated. These are excitation in damaged sensory pathways and the effects of impaired inhibitory pathways.

Evidence for abnormal excitation comes from several sources. Referred to above, epilepsy can be associated with pain, and occasionally epileptic attacks with a painful aura follow strokes. ${ }^{161}$ Furthermore, epileptic activity has been recorded from the midbrain and thalamus of patients with poststroke pain by some workers ${ }^{62}{ }^{63}$ but not others. ${ }^{64}$ Disconnection has been considered a possible factor in patients with pain related to parietal strokes that interrupt sensory pathways between thalamus and cortex, ${ }^{30}$ and the sequelae may represent an example of deafferentation. Deafferentation phenomena, perhaps akin to changes seen in denervation supersensitivity, have been much discussed in relation to those neurophysiological changes in the thalamus that occur in patients with poststroke pain ${ }^{65}$ and other central pains. ${ }^{66}$ These changes include abnormal spontaneous and evoked burst activity, ${ }^{67}$ presence of this activity in medial as well as posteroventolateral neurons, ${ }^{68}$ and loss of point to point relation between thalamic neurons and their usual receptive and projected fields. ${ }^{69}$

Whether such changes relate specifically to pain, however, remains unclear. Thus microelectrode studies in 29 patients with central poststroke pain showed both normal and abnormal receptive and projected fields, leading Tasker in a review that included this study to comment: "Burst-firing cells and somatotopographical reorganisation were found in most patients and bore no relationship to their pain." ${ }^{69}$ Again, whereas neurogenic pain may be associated with cells in the thalamus which show bursting activity with characteristics typical of low threshold calcium spikes, the tendency to generate such bursts is also seen in various other yet painless disorders of the CNS that are associated with positive phenomena. ${ }^{70}$ Furthermore, not only is it unresolved whether neurogenic pain is necessarily associated with excitation in spinothalamic pathways at thalamic or cortical level, but poststroke pain has also been reported in patients whose entire thalamus on one side has been infarcted. ${ }^{71}$ What structures might subserve pain when extensive damage has occurred in the CNS and the question of involvement of ipsilateral and infrathalamic pathways have not been established. ${ }^{69}$

Damage to central inhibitory pathways is likely to be another mechanism involved in the causation of central pain (for review of central inhibition, see ${ }^{72}$ ). Noradrenaline and serotonin are implicated both in the function of these inhibitory pathways and in the effects of tricyclic antidepressants, effects which include the relief of pain. Enhancement of inhibition, either chemically or by means of peripheral and central stimulation, may thus explain the mechanisms underlying some of the therapeutic strategies described.

Although several studies of functional imaging in pain after strokes have been reported, their contribution to understanding poststroke and other central pains is unclear. The bewildering use of different types of metabolic studies using different techniques, the different clinical features of the patients, and the different brain areas that have been investigated mean that correlation of the findings with the clinical phenomena is not possible at present. ${ }^{73}$

Thus in 1988 a PET study by Laterre and colleagues showed decreased glucose metabolism in the affected posterior thalamus in a patient with poststroke thalamic pain. ${ }^{74}$ By comparison, a SPECT study of four patients with central poststroke pain, two of whom had hyperpathia, indicated a relative hyperactivity of the thalamus contralateral to the hyperpathic side. ${ }^{75}$ This hyperactivity was present only in those two patients with hyperpathia; the lesion was thalamic in one patient and in the subcortical parietal region in the other. In another SPECT study assessing cortical involvement in five patients with central pain, in two (one with central poststroke pain, the other with anaesthesia dolorosa) there was decreased parietal blood flow contralateral to the painful $\operatorname{side}^{76}$; a similar 
finding was noted by Lee $e t$ al in three patients with thalamic poststroke pain. ${ }^{77}$ A PET study by Hirato and colleagues disclosed preserved regional oxygen consumption and cortical glucose metabolism in brain structures except in the affected thalamus of patients with thalamic strokes and pain, but in strokes in the putamen and in thalamic strokes without pain, regional cerebral oxygen consumption was reduced. ${ }^{78}$ These authors suggested that different pathophysiological mechanisms might occur under different circumstances, although conclusions could not be reached-a view evidently applicable to all such studies at present.

It should also be emphasised that these changes in functional imaging may not necessarily relate specifically to central poststroke pain. This is because, as with the physiological phenomena recorded from the thalamus, ${ }^{79} 80$ the widespread changes seen on PET are also seen in painful conditions that arise outside the brain. ${ }^{81-83}$ These PET changes included an unexpected decreased thalamic activity contralateral to the symptomatic side in patients whose pain arises peripherally, a finding reminiscent of that reported in the patient with central pain referred to above. ${ }^{74}$ Apart from this question of specificity, it also remains unclear whether the physiological and functional imaging findings relate to the experience of pain, to mechanisms that inhibit pain, or to epiphenomena.

At the end of this century in which pain after stroke became recognised, much has been learnt about the clinical features of this and related conditions, and new techniques have started to contribute to understanding the underlying pathophysiology. It has been established that central poststroke pain, originally thought an uncommon neurological curiosity, is in reality an important and underrecognised condition. Both spontaneous and evoked pains and other sensory disturbances may be present, the pain is often burning in quality, and when sensory changes are slight the most characteristic finding is impaired temperature appreciation in and surrounding the painful area. Management consists of treatment of secondary or associated musculoskeletal and other nociceptive components, drug therapy with tricyclic antidepressants sometimes combined later with anticonvulsants such as carbamazepine, trials of transcutaneous electrical nerve stimulation and occasionally sympathetic blockade, and only very rarely resort to deep brain or the currently experimental motor cortex stimulation. Psychological methods of pain management and occasionally referral for a psychiatrist's opinion may also be very valuable. It is to be hoped that further developments in therapy will reach fruition early in the next century.

I am most grateful to Dr P W Nathan for his valuable comments.

The National Hospital for Neurology and Neurosurgery,

G D SCHOTT Queen Square, London WC1N 3BG, UK

1 Bowsher D. Central pain: clinical and physiological characteristics. $F$ Neurol Neurosurg Psychiatry 1996;61:62-9.

2 Andersen $G$, Vestergaard $K$, Ingeman-Nielsen $M$, Jensen TS. Incidence of central post-stroke pain. Pain 1995;61:187-93.

3 Merskey H, Bogduk N, eds. Classification of chronic pain. Description of chronic pain syndromes and definitions of pain terms. 2nd ed. Seattle: IASP Press, 1994:43.

4 Riddoch G. The clinical features of central pain. Lancet 1938;i: 1093-8;1150-6;1205-9.

5 Cassinari V, Pagni CA. Central pain. A neurosurgical survey. Cambridge MA: Harvard University Press, 1969.

6 Pagni CA. Central pain and painful anesthesia. Prog Neurol Surg 1976; 8:132-257.

7 Casey KL, ed. Pain and central nervous system disease: the central pain syndromes. New York: Raven Press, 1991

8 Bonica JJ. Introduction. In: Nashold BS, Ovelmen-Levitt J, eds. Deafferentation pain syndromes: pathophysiology and treatment. New York Raven Press, 1991:1-19.

9 Clifford DB, Trotter JL. Pain in multiple sclerosis. Arch Neurol 1984; 41:1270-2.

10 Moulin DE, Foley KM, Ebers GC. Pain syndromes in multiple sclerosis. Neurology 1988;38:1830-4.
11 Österberg A, Boivie J, Holmgren H, Thuomas K-Å, Johansson I. The clinical characteristics and sensory abnormalities of patients with central pain caused by multiple sclerosis. Proceedings of the 7th World Congress of Pain. In: Gebhart GF, Hammond DL, Jensen TS, eds. Progress in pain research and management. Vol 2. Seattle: IASP Press, 1994:789-96.

12 Seddall PJ, Taylor D, Cousins MJ. Pain associated with spinal cord injury. Curr Opin Neurol 1995;8:447-50.

13 Rétif J, Brihaye J, Vanderhaegen J, Syndrome douloureux "thalamique" et lésion pariétale. Neurochirurgie 1967;13:375-84.

14 Marshall J. Sensory disturbances in cortical wounds with special reference to pain. $\mathcal{F}$ Neurol Neurosurg Psychiatry 1951:14:187-204.

15 Young GB, Blume WT. Painful epileptic seizures. Brain 1983:106: 537-54.

16 Salanova V, Andermann F, Rasmussen T, Olivier A, Quesney LF. Parieta lobe epilepsy. Clinical manifestations and outcome in 82 patients treated surgically between 1929-1988. Brain 1995;118:607-27

17 Gates P, Nayernouri T, Sengupta RP. Epileptic pain: a temporal focus. $\mathcal{F}$ Neurol Neurosurg Psychiatry 1984;47:319-20.

18 Schott GD. Pain in Parkinson's disease. Pain 1985:22:407-11.

19 Quinn NP, Koller WC, Lang AE, Marsden CD. Painful Parkinson's disease. Lancet 1986;i:1366-9.

20 Newrick PG, Langton-Hewer R. Pain in motor neuron disease. $f$ Neurol Neurosurg Psychiatry 1985:48:838-40.

21 Barnett HJM, Foster JB, Hudgson P. Syringomyelia. London: WB Saunders, 1973: 17-20.

22 Schurch B, Wichmann W. Rossier AB. Post-traumatic syringomyelia (cystic myelopathy): a prospective study of 449 patients with spinal cord injury. $\mathcal{F}$ Neurol Neurosurg Psychiatry 1996:60:61-7.

23 Pelser H, van Gijn J. Spinal infarction. A follow-up study. Stroke 1993;24: 896-8.

24 Willis WD. Central neurogenic pain: possible mechanisms. In: Nashold BS, Ovelmen-Levitt J, eds. Deafferentation pain syndromes: pathophysiology and treatment. New York: Raven Press, 1991:81-102.

25 Dejerine J, Roussy G. Le syndrome thalamique. Rev Neurol (Paris) 1906:14:521-32. English translation in: Rottenberg DA, Hochberg FH, eds. Neurological classics in modern translation. New York: Hafner Press, 1977:189-200. Extract in: Wilkins RH, Brody IA. The thalamic syn1977:189-200. Extract in: Wilkins

26 Leijon G, Boivie J, Johansson I. Central post-stroke pain-neurological symptoms and pain characteristics. Pain 1989:36:13-25.

27 Lewis-Jones H, Smith T, Bowsher D, Leijon G. Magnetic resonance imaging in 36 cases of central post-stroke pain (CPSP). Pain Suppl 1990;5: S278.

28 Vestergaard K, Nielsen J, Andersen G, Ingeman-Nielsen M, ArendtNielsen L, Jensen TS. Sensory abnormalities in consecutive, unselected patients with central post-stroke pain. Pain 1995:61:177-86.

29 Bogousslavsky J, Regli F, Uske A. Thalamic infarcts: clinical syndromes, etiology, and prognosis. Neurology 1988;38:837-48.

30 Schmahmann JD, Leifer D. Parietal pseudothalamic pain syndrome. Clinical features and anatomic correlates. Arch Neurol 1992;49:1032-7.

31 Bowsher DR, Foy PM, Shaw MDM. Central pain complicating infarction following subarachnoid haemorrhage. Br f Neurosurg 1989:3:435-42.

32 Stoodley MA, Warren JD, Oatey PE. Thalamic syndrome caused by unruptured cerebral aneurysm. F Neurosurg 1995;82:291-3.

33 Soria ED, Fine EJ. Disappearance of thalamic pain after parietal subcortical stroke. Pain 1991;44:285-8.

34 Leijon G, Boivie J. Central post-stroke pain-the effect of high and low frequency TENS. Pain 1989;38:187-91.

35 Boivie J, Leijon G, Johansson I. Central post-stroke pain-a study of the mechanisms through analyses of the sensory abnormalities. Pain 1989; 37:173-85.

36 Garcin R, Lepresle J. Deuxième observation personelle de syndrome sensitif de type thalamique et à typographie chéiro-orale par lésion localisée du thalamus. Rev Neurol (Paris) 1960:103:474-81.

37 Triggs WJ, Beric A. Dysaesthesiae induced by physiological and electrical activation of posterior column afferents after stroke. $\mathcal{F}$ Neurol Neurosurg

38 Casey KL, Beydoun A, Boivie J, et al. Laser-evoked cerebral potentials and sensory function in patients with central pain. Pain 1996;64:485-91.

39 Holmgren $\mathrm{H}$, Leijon G, Boivie J, Johansson I, Ilievska L, et al. Central post-stroke pain-somatosensory evoked potentials in relation to location of the lesion and sensory signs. Pain 1990;40:43-52.

40 Bowsher D. The management of central post-stroke pain. Postgrad Med $\mathcal{F}$ 1995;71:598-604.

41 Leijon G, Boivie J. Central post-stroke pain-a controlled trial of amitriptyline and carbamazepine. Pain 1989;36:27-36.

42 Bainton T, Fox M, Bowsher D, Wells C. A double-blind trial of naloxone in central post-stroke pain. Pain 1992;48:159-62.

43 Max MB, Lynch SA, Muir J, Shoaf SE, Smoller B, Dubner R. Effects of desipramine, amitriptyline, and fluoxetine on pain in diabetic neuropathy. N Engl F Med 1992;326:1250-6.

44 Dubner R. A call for more science, not more rhetoric, regarding opioids and neuropathic pain. Pain 1991;47:1-2.

45 Awerbuch GI, Sandyk R. Mexiletine for thalamic pain syndrome. Int $\mathcal{F}$ Neurosci 1990;55:129-33.

46 McQuay HJ, Carroll D, Jadad AR, et al. Dextromethorphan for the treatment of neuropathic pain: a double-blind randomised controlled crossover trial with integral n-of-1 design. Pain 1994;59:127-33.

47 Backonja M, Arndt G, Gombar KA, Check B, Zimmermann M. Response of chronic neuropathic pain syndromes to ketamine: a preliminary study. Pain 1994;56:51-7.

48 Bushnell TG, Craig J. Response of chronic neuropathic pain syndromes to ketamine: a role for nor-ketamine? [letter]. Pain 1995;60:115.

49 Taira T, Tanikawa T, Kawamura H, Iseki H, Takakura K. Spinal intrathecal baclofen suppresses central pain after a stroke [letter] $\mathcal{f}$ Neurol Neurosurg Psychiatry 1994;57:381-2.

50 Siegfried J. Neurosurgical procedures abandoned in the management of pain and perspectives for the future. In: Dimitrijevic MR, Wall PD, Lindblom U, eds. Recent achievements in restorative neurology. 3. Altered sensation and pain. Basel: Karger, 1990:87-91.

51 Loh L, Nathan PW, Schott GD. Pain due to lesions of central nervous system removed by sympathetic block. $B M F$ 1981;282:1026-8.

52 Duncan GH, Bushnell MC, Marchand S. Deep brain stimulation: a review of basic research and clinical studies. Pain 1991;45:49-59. 
53 Boivie J, Meyerson BA. A correlative anatomical and clinical study of pain suppression by deep brain stimulation. Pain 1982;13:113-26.

54 Tsubokawa T, Katayama Y, Yamamoto T, Hirayama T, Koyama S. Chronic motor cortex stimulation in patients with thalamic pain. $\mathcal{F}$ Neurosurg 1993;78:393-401.

55 Hosobuchi Y. Motor cortical stimulation for control of central deafferentation pain. Adv Neurol 1993;63:215-7.

56 Meyerson BA, Lindblom U, Linderoth B, Lind G, Herregodts P. Motor cortex stimulation as treatment of trigeminal neuropathic pain. Acta Neurochir Suppl (Wien) 1993;58:150-3.

57 Peyron R, Garcia-Larrea L, Deiber MP, et al. Electrical stimulation of precentral cortical area in the treatment of central pain: electrophysiological and PET study. Pain 1995;62:275-86.

58 Pither CE. Nicholas MK. Psychological approaches in chronic pain management. Br Med Bull 1991;47:743-61.

59 Marshall JC, Halligan PW. Pain pathways and plasticity. Nature 1993;361: 410.

60 Devinsky O, Morrell MJ, Vogt BA. Contributions of anterior cingulate cortex to behaviour. Brain 1995;118:279-306.

61 Michel D, Laurent B, Convers P, et al. Douleurs corticales. Étude clinique, électrophysiologique et topographique de 12 cas. Rev Neurol (Paris) 1990;146:405-14.

62 Wilson WP, Nashold BS. Epileptic discharges occurring in the mesencephalon and thalamus. Epilepsia 1968;9:265-73.

63 Yamashiro K, Iwayama K, Kurihara M, et al. Neurones with epileptiform discharge in the central nervous system and chronic pain. Experimental discharge in the central nervous system and chronic pain. Experimental and clini $130-2$.

64 Gybels J, Kupers R. Van Calenbergh F. Physiological approach to management of pain. In: Dimitrijevic MR, Wall PD, Lindblom U, eds. Recent achievements in restorative neurology. 3. Altered sensation and pain. Basel: Karger, 1990:79-86.

65 Jensen TS, Lenz FA. Central post-stroke pain: a challenge for the scientist and the clinician. Pain 1995;61:161-4.

66 Lenz FA. Evidence that thalamus is involved in the generation of sensory abnormalities observed in human central pain syndromes. In: Nashold BS, Ovelmen-Levitt J. Deafferentation pain syndromes. Pathophysiology and treatment. New York: Raven Press, 1991:141-50.

67 Hirayama T, Dostrovsky JO, Gorecki J, Tasker RR, Lenz FA. Recordings of abnormal activity in patients with deafferentation and central pain. Stereotact Funct Neurosurg 1989 52:120-6.

68 Rinaldi PC, Young RF, Albe-Fessard D, Chodakiewitz J. Spontaneous neuronal hyperactivity in the medial and intralaminar thalamic nuclei of patients with deafferentation pain. $\mathcal{f}$ Neurosurg $1991 ; 74: 415-21$.
69 Tasker RR. The use of microelectrodes in the human brain. Adv Pain Res Ther 1995;22:143-74.

70 Jeanmonod D, Magnin M, Morel A. Low-threshold calcium spike bursts in the human thalamus. Common physiopathology for sensory, motor and limbic positive symptoms. Brain 1996;119:363-75.

71 Parrent AG, Lozano AM, Dostrovsky JO, Tasker RR. Central pain in the absence of functional sensory thalamus. Stereotact Funct Neurosurg 1992; 59:9-14.

72 Jones SL. Descending control of nociception. In: Light AR, ed. The initial processing of pain and its descending control: spinal and trigeminal systems. processing of pain and its descend

73 Berman J. Imaging pain in humans. Br F Anaesth 1995;75:209-16.

74 Laterre EC, De Volder AG, Goffinet AM. Brain glucose metaboliosm in thalamic syndrome. $₹$ Neurol Neurosurg Psychiatry 1988;51:427-8.

75 Cesaro $\mathrm{P}$, Mann MW, Moretti JL, et al. Central pain and thalamic hyperactivity: a single photon emission computerized tomographic study. Pain 1991;47:329-36.

76 Canavero S, Pagni CA, Castellano G, et al. The role of cortex in centra pain syndromes: preliminary results of a long-term technetium-99 hexamethylproyleneamineoxime single photon emission computed tomography study. Neurosurgery 1993;32:185-91.

77 Lee MS, Choi IS, Chuno JS. Thalamic syndrome and cortical hypoperfusion on technetium-99m HM-PAO brain SPECT. Yonsei Med f 1989;30: 151-7. Cited in: Chen ACN. Human brain measures of clinical pain: a review. II. Tomographic imagings. Pain 1993;54:133-44.

78 Hirato M, Kawashima Y, Shibazaki T, Shibasaki T, Ohye C. Pathophysiology of central (thalamic) pain: a possible role of the intralaminar physiology of central (thalamic) pain: a possible role of the intralaminar

79 Lenz FA, Kwan HC, Dostrovsky JO, Tasker RR. Characteristics of the bursting pattern of action potentials that occurs in the thalamus of patients with central pain. Brain Res 1989;496:357-60.

80 Lenz FA, Kwan HC, Martin R, Tasker R, Richardson RT, Dostrovsky JO et al. Characteristics of somatotopic organization and spontaneous neuronal activity in the region of the thalamic principal sensory nucleus in patients with spinal cord transection $\mathcal{F}$ Neurophysiol 1994;72:1570-87.

81 Di Piero V, Jones AKP, Iannotti I, et al. Chronic pain: a PET study of the central effects of percutaneous high cervical cordotomy. Pain 1991;46: 9-12.

82 Hsieh J-C, Belfrage M, Stone-Elander S, Hansson P, Ingvar M. Central representation of chronic ongoing neuropathic pain studied by positron representation of chronic ongoing neuropathic

83 Iadarola MJ, Max MB, Berman KF, et al. Unilateral decrease in thalamic activity observed with positron emission tomography in patients with chronic neuropathic pain. Pain 1995;63:55-64. 